\title{
Article \\ Synthesis and Properties of Polyimide Silica Nanocomposite Film with High Transparent and Radiation Resistance
}

\author{
Jindong Huang ${ }^{1,2}$, Guanglu Zhang ${ }^{1,2}$, Beiping Dong ${ }^{1}$ and Juncheng Liu ${ }^{1, *}$ \\ 1 School of Materials Science and Engineering, Tiangong University, Tianjin 300387, China; \\ jdhuang@tiangong.edu.cn (J.H.); zgltg@tiangong.edu.cn (G.Z.); 1931025097@tiangong.edu.cn (B.D.) \\ 2 School of Physical Science and Technology, Tiangong University, Tianjin 300387, China \\ * Correspondence: jchliu@tiangong.edu.cn; Tel.: +86-(0)-22-83-955-811
}

check for updates

Citation: Huang, J.; Zhang, G.; Dong B.; Liu, J. Synthesis and Properties of Polyimide Silica Nanocomposite Film with High Transparent and Radiation Resistance. Nanomaterials 2021, 11, 562. https://doi.org/10.3390/ nano11030562

Academic Editor: Alexander Kromka

Received: 28 January 2021

Accepted: 21 February 2021

Published: 24 February 2021

Publisher's Note: MDPI stays neutral with regard to jurisdictional claims in published maps and institutional affiliations.

Copyright: (C) 2021 by the authors. Licensee MDPI, Basel, Switzerland. This article is an open access article distributed under the terms and conditions of the Creative Commons Attribution (CC BY) license (https:// creativecommons.org/licenses/by/ $4.0 /)$.

\begin{abstract}
In order to prepare flexible glass cover sheet materials suitable for space solar cells, fluorinated diamine 2,2'-bistrifluoromethyl benzidine (TFDB) and fluorinated dianhydride 4,4' (hexafluoroisopropyl) diphthalic dianhydride (6FDA) as the monomer, polyimide (PI) $/ \mathrm{SiO}_{2}$ composite film was synthesized by in situ polymerization, and the influence of coupling agent and $\mathrm{SiO}_{2}$ nanoparticle content on the film structure and properties was studied. The results show that PI synthesized from fluorine-containing monomers has better light transmittance, and the highest transmittance can reach 91.4\%. The average visible light transmittance of the composite film decreases with the increase of $\mathrm{SiO}_{2}$ content, and the transmittance of the film decreases less in the high-wavelength region and greatly decreases in the low-wavelength region. The tensile strength and elastic modulus of $\mathrm{PI} / \mathrm{SiO}_{2}$ composite film increase with the increase of $\mathrm{SiO}_{2}$ content, first increase and then decrease, reaching the maximum when the content is $10 \%$; while the elongation at break of the composite film gradually increases with the increase of $\mathrm{SiO}_{2}$ content reduce. The thermal stability of $\mathrm{PI} / \mathrm{SiO}_{2}$ composite film increases with the increase of $\mathrm{SiO}_{2}$ content. The doping of nano-SiO 2 significantly suppresses the influence of irradiation on the mechanical properties of the film.
\end{abstract}

Keywords: polyimide; nano- $\mathrm{SiO}_{2}$; in situ polymerization; transmittance; radiation resistance; mechanical properties

\section{Introduction}

With the rapid development of aerospace technology, flexible space solar cells are urgently needed. Flexible solar cells need to be protected by glass cover sheets due to the presence of atomic oxygen $(\mathrm{AO})$, ultraviolet rays, various cosmic ray radiation, and micrometeoroids in the space environment. The glass cover sheet of the flexible solar cell should possess sufficient flexibility and good mechanical properties, moreover, high light transmittance, resistance to ultraviolet rays and various cosmic rays. Therefore, it is urgent to find an alternative material for space solar cell glass cover sheets with the above comprehensive performances.

Polyimide ("PI" for short) is a type of polymer whose main chain is an aromatic ring and an imide ring as the main structural units. It has excellent comprehensive properties, such as high creep resistance, high electrical insulation, low thermal expansion coefficient, low dielectric constant, etc., with excellent high and low-temperature resistance and corrosion resistance. PI plays an increasingly important role in the fields of microelectronics, optical devices, power and electrical, aerospace and other fields [1-3]. However, besides flexibility, pure PI is difficult to meet other requirements of space solar cell glass cover sheets, such as high light transmittance and high radiation resistance.

In order to improve the light transmittance of PI, Tao et al. [4,5] prepared a series of polyimide hybrid films by polymerizing 2,2'-bis trifluoromethyl benzidine and 4,4'hexafluoroisopropyl diphthalic anhydride and adding different contents of dodecyl triphenyl phospho-mica. The light transmittance of these hybrid films was up to $90 \%$ at $450 \mathrm{~nm}$. 
The above polyimide membranes with fluorinated substituents introduced into the molecular chain generally have high transparency, excellent thermal stability and low dielectric constant. However, the relatively high synthesis cost of fluorinated monomers has limited the industrialization process of fluorinated polyimide membranes to some extent. In addition, the mechanical properties and thermal stability of the general fluorinated PI are relatively poor. Appropriate reinforcing materials should be introduced to improve the comprehensive properties of the composites.

In order to improve the radiation resistance of $\mathrm{PI}$, Wang et al. [6] reported nano- $\mathrm{SiO}_{2}$ filled glass fiber/PI composite material, which was used as a resin for spacecraft. The research results displayed that the corrosion resistance of the composite material in the atomic oxygen environment was significantly enhanced, indicating that $\mathrm{SiO}_{2}$ was beneficial to enhance the system's resistance to space radiation and atomic oxygen. Li et al. [7] prepared transparent PI film through the reaction between phosphorous-containing fluorinecontaining aromatic diamine monomer 2,5-bis [(4-amino-2-trifluoromethylphenoxy)phenyl] diphenylphosphine oxide and the commercialized aromatic dianhydride. The obtained PI film had good solubility, heat resistance and mechanical properties in organic solvents but also exhibited that the introduction of diphenylphosphine oxide side groups (DPO), fluorine, all meta-position could improve the light transmittance and atomic oxygen resistance of the material.

In order to improve the mechanical properties of PI, Hu et al. [8] added carbon nanotubes to the polyimide and searched for the best ratio. Finally, the composite material with the best room temperature mechanical properties was obtained when $0.2 \%$ carbon nanotubes were added. Huang et al. [9] synthesized a new type of aminopropyl isobutyl POSS with single apex activity, which was used to form a composite film material with PMDA and ODA. This material showed excellent mechanical properties, with a tensile strength of $148 \mathrm{MPa}$ and elongation at break up to $98 \%$. Cheng Jingdong [10] used silica sol as the silicon source to prepare $\mathrm{PI} / \mathrm{SiO}_{2}$ nano-hybrid films via in situ polymerization. With the increase of $\mathrm{SiO}_{2}$ content, the modulus of elasticity increased linearly. The tensile strength and elongation at break increased first and then decreased with the increase of $\mathrm{SiO}_{2}$ content and reached the maximum value when the $\mathrm{SiO}_{2}$ content was $3 \%$. Li et al. [11] also found that the increase in the compatibility of $\mathrm{SiO}_{2}$ and $\mathrm{PI}$ increased the tensile strength and elongation at the break of the composite film. They reached the highest value when the content of $\mathrm{SiO}_{2}$ was $5 \%$ and decreased when the content continued to increase.

In order to improve the thermal stability of PI, Mazov et al. [12] used a phase inversion method to embed unprocessed single-walled carbon nanotubes as a filler into a polyimide matrix to synthesize a PI/r-MWCNTs film. It showed that with increasing the concentration of filler r-MWCNTs, the thermodynamic properties of PI/r-MWCNTs film would be improved. Shahram et al. [13] used pyromellitic dianhydride and common diamines as polymerized monomers to prepare nanoscale PI film, which illustrated that the film had good stability at a high temperature of $370^{\circ} \mathrm{C}$. Boroglu et al. [14] used ODA and PMDA as monomers, trimethoxyvinylsilane (TMVS) as an inorganic precursor to prepare $\mathrm{PI} / \mathrm{SiO}_{2}$ hybrid films. The TGA test suggested that there was no weight loss before $400{ }^{\circ} \mathrm{C}$, indicating the addition of $\mathrm{SiO}_{2}$ has improved the heat resistance of the film. With the increase of $\mathrm{SiO}_{2}$ content, the $\mathrm{Tg}$ of the film increased by $7 \sim 28^{\circ} \mathrm{C}$.

$\mathrm{PI} / \mathrm{SiO}_{2}$ nanoparticle composite materials have become one of the research hotspots. The interface incompatibility between the inorganic filler $\mathrm{SiO}_{2}$ and the polyimide matrix results in the reduction of mechanical properties, polyimide molecular chain structure and crystallinity, and further affects the electrical insulation properties of polyimide materials. Because there are a large number of unsaturated residual bonds and hydroxyl groups in different bonding states on the surface of nano- $\mathrm{SiO}_{2}$, it is open to researchers to design the surface by controlling the balance of these unsaturated and unstable states to improve its compatibility with polymer polymerization. Through the design, the compatibility and dispersion of nano- $\mathrm{SiO}_{2}$ and the polymer matrix can be improved. The in situ polymerization process makes two different components to maximize the synergy effect. The in situ poly- 
merization method is to add nanoparticles in the process of monomer polymerization and prepare nanocomposite materials through a further polymerization reaction. This method makes the nanoparticles more uniformly dispersed in the polymer matrix, which not only maintains the original structure and state of the nanoparticles but also enables the various groups on the surface of the nanoparticles to fully interact with the polymer molecules physically or chemically. Different interface operations between nanoparticles and polymer matrix have different effects on the properties of the matrix polymer.

In addition, the use of coupling agents is another dispersing method for chemical modification of the surface of nanoparticles after mechanical stirring and ultrasonic vibration. The surface free energy of the particles after surface modification will decrease, which benefits to reduce agglomerate. It is easy to obtain smaller nanoscale particles, which is conducive to the uniform dispersion of the nanoparticles in the organic matter and increases the interaction with the organic matrix. It is beneficial to obtain composite materials with better light transmittance and mechanical properties [15].

In this work, a series of $\mathrm{PI} / \mathrm{SiO}_{2}$ composite films with different $\mathrm{SiO}_{2}$ content were prepared by in situ polymerization method, in which nano-SiO 2 particles (about $15 \mathrm{~nm}$ in diameter) were used as the silicon source, and KH560 was selected as the silane coupling agent for surface modification, and 2,2'-bistrifluoromethylbenzidine (TFDB) and 4,4' (Hexafluoroisopropyl) bisphthalic dianhydride (6FDA) was used as the monomer raw material. Fourier-transform infrared analysis (FT-IR), scanning electron microscopy (SEM), thermal weight loss analysis (TGA), ultraviolet-visible photometer and ultraviolet radiation simulator were used to investigate the bonding situation and microscopic morphology, thermal properties, optical properties, mechanical properties and UV resistance.

\section{Materials and Methods}

\subsection{Preparation of $\mathrm{PI} / \mathrm{SiO}_{2}$ Films}

2,2'-Bistrifluoromethyl benzidine (TFDB, analytical purity 99\%), 4,4' (hexafluoroisopropyl) diphthalic acid Anhydride (6FDA, analytical purity 99\%), and $\mathrm{SiO}_{2}$ nanoparticles(particle diameter of about $15 \mathrm{~nm}$ ) were purchased from Shanghai Macklin Biochemical Technology Co., Ltd. (Shanghai, China). N, N'-Dimethylacetamide (DMAc, analytical purity 99\%) and silane-coupling agent (KH-560, 98\%) were purchased from Shanghai Jingchun Biochemical Technology Co., Ltd. (Shanghai, China). The molecular formula of the above chemical agents is shown in Figure S1. The XRD spectrum of the $\mathrm{SiO}_{2}$ nanoparticles we purchased is shown in Figure S2.

We weighed the nano- $\mathrm{SiO}_{2}$ particles of the required components in a drying beaker and dried it at $120^{\circ} \mathrm{C}$ for $2 \mathrm{~h}$. We weighed a certain mass of diamine in the drying beaker and dried it at $120^{\circ} \mathrm{C}$ for $4 \mathrm{~h}$. We weighed a certain mass of the dianhydride (molar ratio of TFDB and 6FDA $=1: 1.02$ ) and placed it in a drying beaker, and dried it at $180{ }^{\circ} \mathrm{C}$ for $4 \mathrm{~h}$. The above raw materials were all dried under a normal laboratory atmosphere. The sample number and raw material ratio were shown in Table S1.

The dried $\mathrm{SiO}_{2}$ nanoparticles were dispersed in an appropriate amount DMAc at room temperature until a homogeneous solution was obtained. Then, a silane coupling agent (KH560) was added to the above solution with ultrasonic treatment for $2 \mathrm{~h}$. After the $\mathrm{SiO}_{2}$ nanoparticles were uniformly dispersed and dissolved in DMAc, the dried diamine was added with continuously stirring. A colorless and transparent solution was obtained. During the whole process, the temperature was kept at $0{ }^{\circ} \mathrm{C}$, and the atmosphere was nitrogen-protected. We added the dried dianhydride into the beaker in batches and added the next batch once it was completely dissolved. When approaching the equivalent point (molar ratio of TFDB and 6FDA $=1: 1.02$ ), the viscosity suddenly increased, and the phenomenon of Weissenberg pole-climbing occurred. For ease of laying the film, DMAc solvent could be appropriately added to keep the solid content of the system at about $10 \%$. After this, the above solution was continuously stirred at room temperature for $24 \mathrm{~h}$ until a colorless or light yellow transparent solution formed, which was further allowed to stand at $0{ }^{\circ} \mathrm{C}$ for $4 \mathrm{~h}$. 
The $5 \mathrm{~cm} \times 5 \mathrm{~cm}$ transparent glass plate was first cleaned by alcohol and dried in an oven at $80^{\circ} \mathrm{C}$ for 30 min. A certain amount of polyamic acid (PAA) $/ \mathrm{SiO}_{2}$ in $\mathrm{DMAc}$ solution was coated on the glass plate by using a glass rod. Then, we used an automatic film scraper to control the thickness of the film to about $20 \mu \mathrm{m}$. The above sample was placed in a $40{ }^{\circ} \mathrm{C}$ oven for $2 \mathrm{~h}$. Then, then a stepped heating method $\left(60{ }^{\circ} \mathrm{C}, 1 \mathrm{~h} ; 70{ }^{\circ} \mathrm{C}, 1 \mathrm{~h} ; 80{ }^{\circ} \mathrm{C}\right.$, $1 \mathrm{~h} ; 100{ }^{\circ} \mathrm{C}, 1 \mathrm{~h} ; 200{ }^{\circ} \mathrm{C}, 1 \mathrm{~h} ; 300{ }^{\circ} \mathrm{C}, 1 \mathrm{~h} ; 350{ }^{\circ} \mathrm{C}, 1 \mathrm{~h}$ ) was used for the thermal imidization treatment. After the temperature of the sample decreased to room temperature, the sample was soaked in a distilled water bath for about $10 \mathrm{~min}$. After the film was separated from the glass plate, the film was soaked in acetone solution for about $5 \mathrm{~min}$, and then was dried in an oven at $80{ }^{\circ} \mathrm{C}$ for $10 \mathrm{~min}$. The obtained $\mathrm{PI} / \mathrm{SiO}_{2}$ composite film was stored in a sealed bag for testing. Moreover, the PI $/ \mathrm{SiO}_{2}$ composite films with 5\%,10\%, 20\% and 30\% $\mathrm{SiO}_{2}$ doping were labelled PIS05, PIS10, PIS20 and PIS30, respectively.

\subsection{Characterization}

The molecular structure, microstructure, thermal stability and optical transmittance performance of $\mathrm{PI} / \mathrm{SiO}_{2}$ composite films were measured using a Fourier-transform infrared spectrometer (Nicolet iS50, Thermo Fisher, Waltham, MA, USA), scanning electron microscope (Gemini SEM500, ZEISS, Heidenheim, Germany), simultaneous thermal analysis (STA 449F5, NETZSCH, Bavaria, Germany), ultraviolet-visible-near-infrared photometer (UH4150, HITACHI, Tokyo, Japan) and UV Solutions, which is the supporting software of UH4150. The mechanical performance was measured on the material universal testing machine (AGS-X 50N, SHIMADZU, Tokyo, Japan). The PI/SiO 2 films can be cut into $5 \mathrm{~cm}$ $\times 1 \mathrm{~cm}$ dumbbell-shaped splines. The tension was $10 \mathrm{~mm} / \mathrm{min}$. The radiation resistance of the $\mathrm{PI} / \mathrm{SiO}_{2}$ films was tested using an ultraviolet lamp (HJ-1402, Cnlight, Foshan, China) to simulate a space irradiation experiment to examine changes in the light transmittance and mechanical properties of the composite film before and after irradiation.

\section{Results and Discussion}

The changes in the absorption peaks of the corresponding functional groups of PI and $\mathrm{PI} / \mathrm{SiO}_{2}$ nanocomposite films were analyzed by using an FT-IR infrared spectrometer. Some of the most commonly used wave numbers for studying the imidization process are shown in Table S2. The FT-IR spectra of the composite films with different $\mathrm{SiO}_{2}$ content are shown in Figure 1. There are four main peaks for all the composite films with different $\mathrm{SiO}_{2}$ content located at $1784 \mathrm{~cm}^{-1}, 1725 \mathrm{~cm}^{-1}, 1375 \mathrm{~cm}^{-1}$ and $717 \mathrm{~cm}^{-1}$, corresponding to asymmetry extensional vibration absorption peak of $\mathrm{C}=\mathrm{O}$, the symmetrical extensional vibration absorption peak of $\mathrm{C}=\mathrm{O}$, the extensional vibration absorption peak of imine ring $\mathrm{C}-\mathrm{N}-\mathrm{C}$, and the flexural vibration absorption peak of $\mathrm{C}=\mathrm{O}$. In addition, there is no absorption peak of amide bond at $1660 \mathrm{~cm}^{-1}$ in all samples, indicating that the thermal imidization process was complete [16].

There is a clear difference at $1000-1100 \mathrm{~cm}^{-1}$ between PI and PI/SiO 2 composites films after comparing all the FT-IR spectra. The characteristic absorption peak of the Si$\mathrm{O}-\mathrm{Si}$ bond appears at $1084 \mathrm{~cm}^{-1}$. With the increase of $\mathrm{SiO}_{2}$ content, the characteristic absorption peak of the $\mathrm{Si}-\mathrm{O}-\mathrm{Si}$ bond gradually broadens. The asymmetric stretching vibration absorption peak of the cyclic $\mathrm{Si}-\mathrm{O}-\mathrm{Si}$ bond appears at $1174 \mathrm{~cm}^{-1}$, suggesting that the organic/inorganic components in the composite system exist in the form of chemical bonds, forming a crosslinked spatial network structure, namely $\mathrm{PI} / \mathrm{SiO}_{2}$ strong interaction composite structure. 


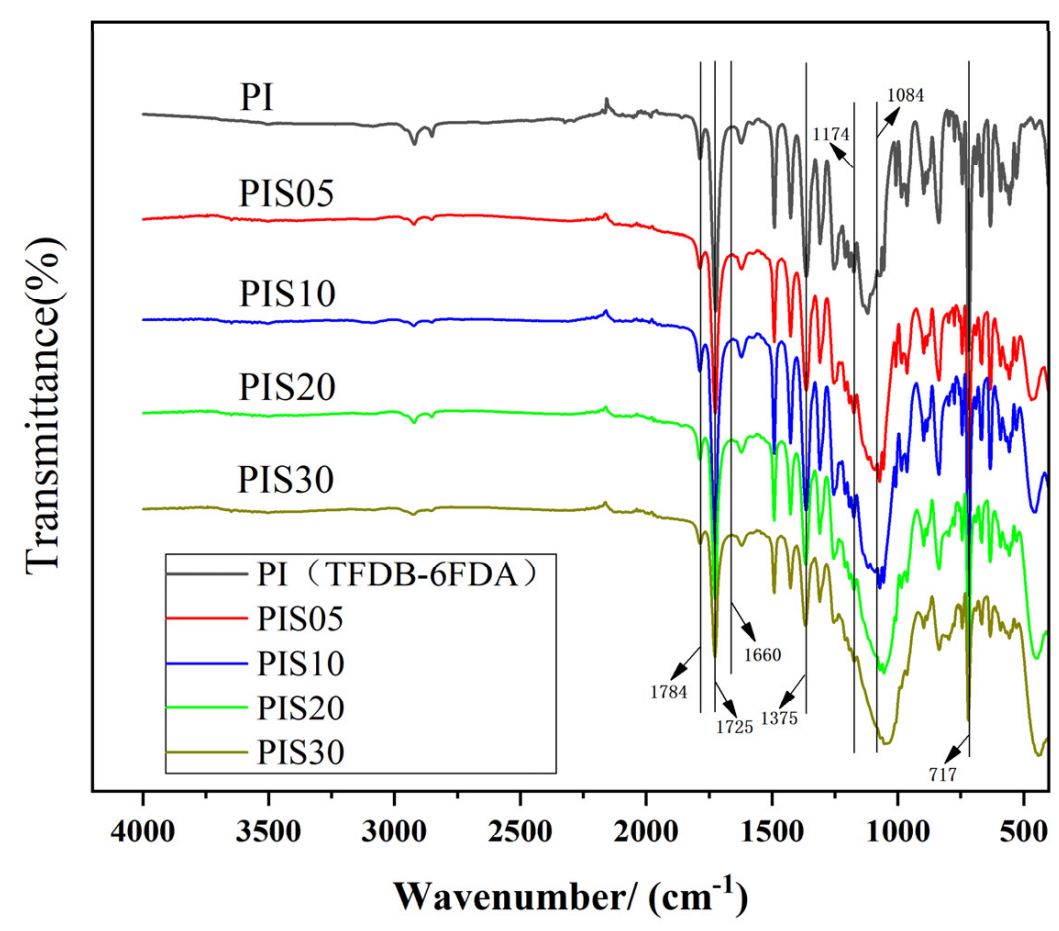

Figure 1. FT-IR spectra of polyimide (PI) $/ \mathrm{SiO}_{2}$ films with various $\mathrm{SiO}_{2}$ contents.

It can be seen from Figure 2 that the composite film prepared by the in situ polymerization method is more conducive to the dispersion of nano- $\mathrm{SiO}_{2}$ in the polymer matrix than the film prepared by other methods. With the increase of $\mathrm{SiO}_{2}$ content, the interaction between the nanoparticles increases, and the phenomenon of aggregation and even partial agglomeration gradually appears, which causes the particle size of $\mathrm{SiO}_{2}$ to increase from about $15 \mathrm{~nm}$ in (a) to about $50 \mathrm{~nm}$ in (b). Further increasing the amount of $\mathrm{SiO}_{2}$ addition, (e) and (f) can see obvious agglomeration. Moreover, the distribution and the size of the particles are not uniform, in, which the largest particle diameter can reach about $400 \mathrm{~nm}$, and the smallest is about $50 \mathrm{~nm}$.

The samples without coupling agents still maintain the advantages of in situ polymerization method of relatively uniform dispersion of inorganic particles. However, compared with the same proportion of $\mathrm{SiO}_{2}$ (comparison between a and c), it is not difficult to find that the $\mathrm{SiO}_{2}$ nanoparticles of the sample using the coupling agent are relatively small in size, showing a network structure crosslinked with PI and uniformly dispersed in among them. This is because there are three ethoxy groups in the molecular chain of the precursor $\mathrm{KH} 560$, all of which are connected to silicon atoms. When the $\mathrm{SiO}_{2}$ content is low, the generated $\mathrm{SiO}_{2}$ content is also relatively low, and the particle size of $\mathrm{SiO}_{2}$ particles is also smaller, gradually forming a continuous network structure of $\mathrm{SiO}_{2}$. They penetrate into the PI, and the surface of the $\mathrm{SiO}_{2}$ particles is covered with an organic phase, which acts as a physical barrier, making the $\mathrm{SiO}_{2}$ nanoparticles difficult to agglomerate. However, when the content of the inorganic phase in the system is too high, as shown in (e) and (f), the use of coupling agents has no significant effect on reducing the size of inorganic nanoparticles. When the content of inorganic matter in the system is too high, $\mathrm{SiO}_{2}$ particles increase and the agglomeration effect between $\mathrm{SiO}_{2}$ particles is enhanced, so the coupling agent has little effect. 


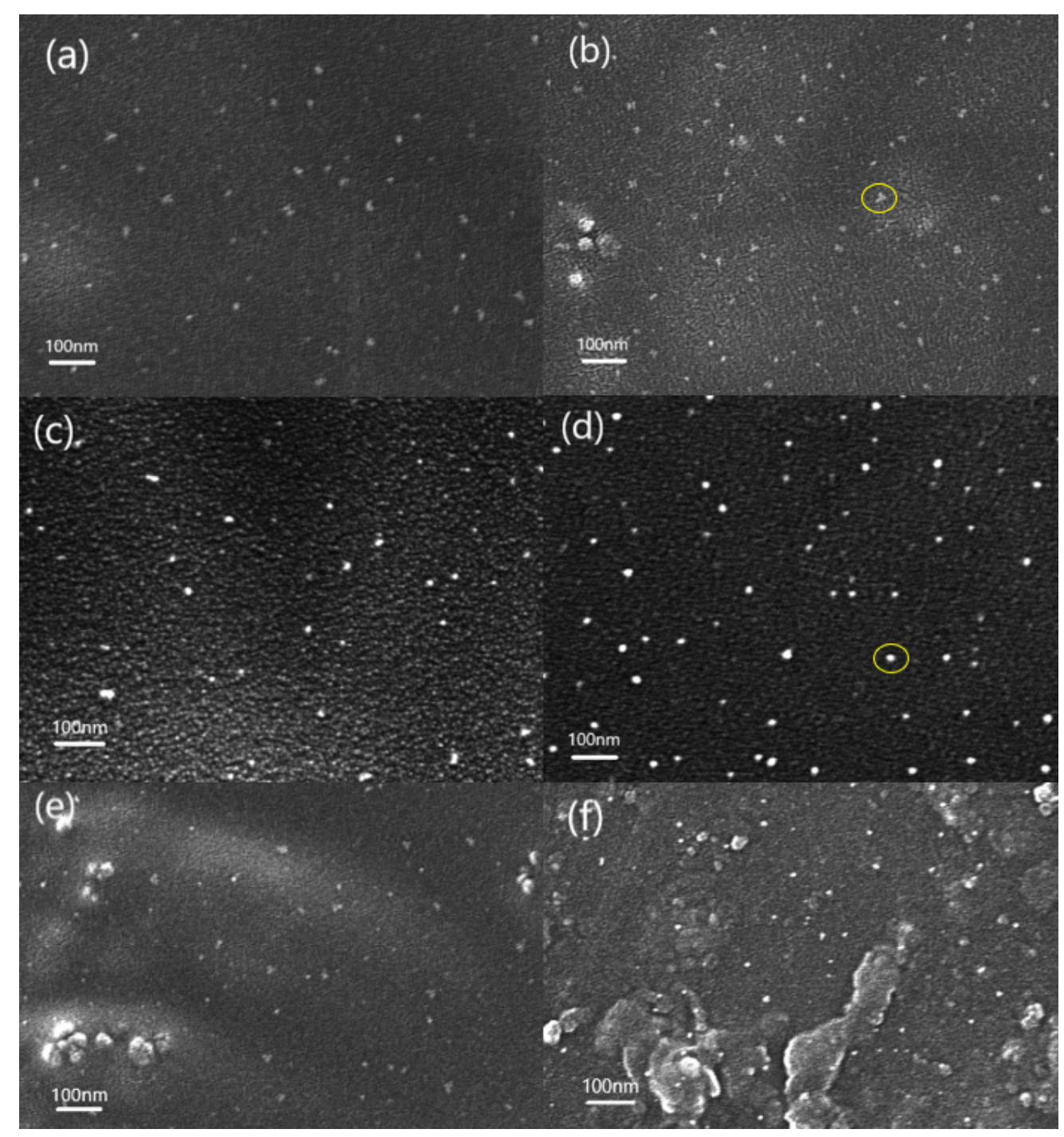

Figure 2. SEM images of PIS05 (a), PIS10 (b), PIS20 (e) and PIS30 (f) with KH560 coupling agent, PIS05 (c) and PIS10 (d) without KH560 coupling agent.

In addition, through comparing the yellow circles in Figure $2 b, d$, it can be found that the interface between the two phases of the sample with the coupling agent is relatively blurred compared with the sample without the coupling agent. This is because the addition of the coupling agent provides a large number of bonding points for the bond between the organic phase and the inorganic phase, which can improve the compatibility between the organic phase and the inorganic phase, resulting in the relative blurry on the interface between the two phases.

The color of traditional PI films (such as the aromatic PI in the ODA-PMDA system) changes from yellow to brown or even dark brown. Its transmittance in the visible light range (wavelength $400-700 \mathrm{~nm}$ ) is low, less than $40 \%$ at $500 \mathrm{~nm}$, and almost $100 \%$ absorption near $400 \mathrm{~nm}$ [17]. This is because traditional aromatic PI film has a large number of C-H bonds in the main chain which has strong conjugation and is easy to form intra- and intermolecular charge transfer complexes (CTC). Hence, the transmittance of this film in the visible light region is poor, and the color is darker.

At present, the basic principle for improving the transparency of PI films is to avoid or reduce the existence of conjugated units and reduce the charge transfer effect within or between molecules. The common methods are as follows: The introduction of fluorinecontaining substituents into the PI molecular structure inhibits the formation of CTC due to the larger electronegativity of fluorine atoms. The introduction of meta-substitution 
structure or asymmetric structure into the PI molecular structure can also reduce the formation of CTC. The reduced content of aromatic structure in the PI molecular structure, such as using alicyclic monomers, helps to reduce the probability of CTC formation [18].

We found that the PI synthesized using diamine and dianhydride monomers containing fluorine substituents not only has the best transmission performance among the above three methods but also the cutoff wavelength extends from about $400 \mathrm{~nm}$ to about $350 \mathrm{~nm}$. Therefore, TFDB-6FDA system PI is selected as the matrix material to prepare $\mathrm{PI} / \mathrm{SiO}_{2}$ composite film. The optical transmittance of multiple samples is measured and compared with the traditional aromatic PI (ODA-PMDA system) film.

As shown in Figure 3, it can be observed that the transmittance of the TFDB-6FDA system PI film at around $400 \mathrm{~nm}$ has reached a high level (above 85\%) and can reach $91.4 \%$ in the visible light range. However, the transmittance of traditional aromatic PI (ODA-PMDA system) film is almost $0 \%$ at about $400 \mathrm{~nm}$ and can only reach about $65 \%$ in the visible light range. The maximum transmittance of the $\mathrm{PI} / \mathrm{SiO}_{2}$ composite film with various $\mathrm{SiO}_{2}$ doping displays obvious changes in the visible light region. The transmittance of the PIS05, PIS10, PIS20 and PIS30 films are 90.7\%, 90\%, 88.6\%, 86.5\%, respectively. However, the transmittances at around $500 \mathrm{~nm}$ are $84.7 \%, 79.8 \%, 67.4 \%, 55.6 \%$, respectively, suggesting the doping of $\mathrm{SiO}_{2}$ nanoparticles affects the light transmittance of the composite film. With the gradual increase of the $\mathrm{SiO}_{2}$ content, an inorganic phase with a large size is gradually formed, which would result in the gradually decreased transmittance of the film. Moreover, the difference is small in the high wavelength region and large in the low wavelength region. This is mainly because as the content of nano- $\mathrm{SiO}_{2}$ particles increases, the probability of interaction between nanoparticles is also increasing. The particle size of some particles gradually increases due to agglomeration, and some have exceeded $100 \mathrm{~nm}$, resulting in microphase separation of $\mathrm{PI} / \mathrm{SiO}_{2}$ composite $[19,20]$, thereby affecting the optical properties of composite materials.

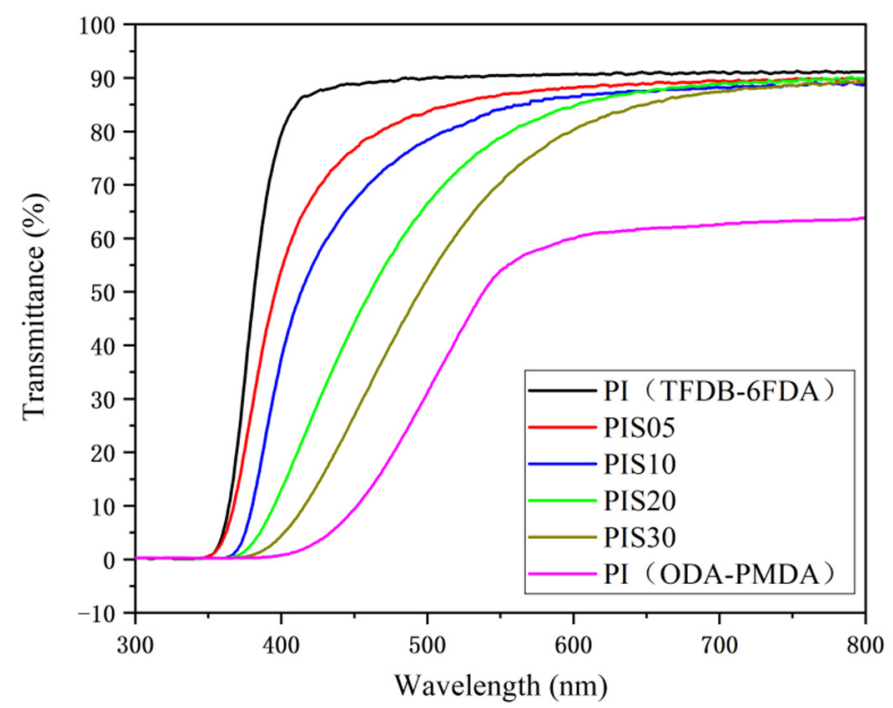

Figure 3. The transmittance of the TFDB-6FDA system PI film, PIS05, PIS10, PIS20, PIS30 and the ODA-PMDA system PI film.

Investigating the mechanical properties of polymer matrix composites, tensile strength, elastic modulus and elongation at break are three essential indicators. As shown in Table 1, as the content of $\mathrm{SiO}_{2}$ increases, the tensile strength and elastic modulus of the $\mathrm{PI} / \mathrm{SiO}_{2}$ films both increase first and then decrease. When the content of $\mathrm{SiO}_{2}$ is low, the inorganic particles are well dispersed in the organic polymer matrix. The $\mathrm{SiO}_{2}$ nanoparticles and the polymer chain form a crosslinked spatial network structure, which makes the organic and inorganic phases tightly connected, thus having a good mechanical enhancement effect. When the $\mathrm{SiO}_{2}$ content reaches $10 \%$, the tensile strength and elastic modulus exhibit the maximum 
value. However, as the $\mathrm{SiO}_{2}$ content continues to increase, on one hand, the increase in the number of inorganic particles makes the distance between the particles gradually decrease. On the other hand, due to the steric hindrance of the polyamic acid molecular chain, longer molecules chain is easy to curl to produce a wrapping effect, which makes the inorganic particles easy to agglomerate and produces larger silica particles. Hence, the distance between the polyimide molecular chains and the gap between the organic and inorganic phases increase at the same time, which reduces the interaction between them, and thus appears the decrease of tensile strength and elastic modulus. With the increase of $\mathrm{SiO}_{2}$ content, the elongation at break of the $\mathrm{PI} / \mathrm{SiO}_{2}$ films gradually decreases due to the rigid $\mathrm{SiO}_{2}$ nanoparticles restrict the movement of the PI polymer chain. The agglomeration caused by the increasing number of nanoparticles forms stress concentration points under the action of external forces, which leads to the toughness deterioration of the $\mathrm{PI} / \mathrm{SiO}_{2}$ films. When the $\mathrm{SiO}_{2}$ content reaches $10 \%, \mathrm{SiO}_{2}$ is still dispersed in the PI matrix in the form of single particles, so the effective contact between the two phases is the largest. The interaction is the strongest, and the effect of enhancing the mechanical properties is the best. Further increasing the content of the inorganic phase, some $\mathrm{SiO}_{2}$ nanoparticles will agglomerate, resulting in the reduction of the effective contact between the two phases and weakening of the interaction, thereby reducing the strengthening effect of $\mathrm{SiO}_{2}$ on the matrix.

Table 1. The mechanical properties of $\mathrm{PI} / \mathrm{SiO}_{2}$ films with various $\mathrm{SiO}_{2}$ contents.

\begin{tabular}{cccccc}
\hline \multirow{2}{*}{ Mechanical Properties } & \multicolumn{5}{c}{ Content of $\mathbf{S i O}_{\mathbf{2}} \mathbf{( \% )}$} \\
\cline { 2 - 6 } & $\mathbf{0}$ & $\mathbf{5}$ & $\mathbf{1 0}$ & $\mathbf{2 0}$ & $\mathbf{3 0}$ \\
\hline Tensile strength (MPa) & 168 & 187 & 198 & 189 & 171 \\
Elastic modulus (GPa) & 2.08 & 2.27 & 2.64 & 2.19 & 2.05 \\
Elongation at break (\%) & 18.2 & 16.7 & 12.8 & 8.9 & 7.3 \\
\hline
\end{tabular}

In addition, with the increase of $\mathrm{SiO}_{2}$ content, the elongation at break of the composite film gradually decreases, which may be because a large number of $\mathrm{SiO}_{2}$ particles destroy the molecular chain structure of polyimide, thus reducing the intermolecular force of polyimide.

Figure 4 shows the TGA curves of $\mathrm{PI} / \mathrm{SiO}_{2}$ composite films with different $\mathrm{SiO}_{2}$ content. It can be seen from the figure that with the increase of $\mathrm{SiO}_{2}$ content, the decomposition temperature of $\mathrm{PI} / \mathrm{SiO}_{2}$ material increases, and the thermal decomposition temperature of PI film, PIS5 film and PIS10 film are $517^{\circ} \mathrm{C}, 522^{\circ} \mathrm{C}$ and $525^{\circ} \mathrm{C}$, respectively. In addition, the residual rate at $700{ }^{\circ} \mathrm{C}$ also increased with the increase of $\mathrm{SiO}_{2}$ content. There are two main reasons for the increase in thermal stability of $\mathrm{PI} / \mathrm{SiO}_{2}$ composite films: First, $\mathrm{SiO}_{2}$ particles have excellent heat resistance. When they are uniformly dispersed in the polyimide matrix at the nanometer level, they will form a crosslinked structure between the carbonyl group in the polyimide molecular chain and the silyl hydroxyl group of $\mathrm{SiO}_{2}$. To a certain extent, the thermal vibration of PI is inhibited, thereby helping to improve thermal stability. As the content of $\mathrm{SiO}_{2}$ increases, the degree of crosslinking also increases, thermal stability is also improving. Second, the nano $\mathrm{SiO}_{2}$ particles are connected to the polyimide main chain through the action of the silane coupling agent, which further restricts the thermal movement of the polyimide macromolecular chain. The more $\mathrm{SiO}_{2}$ added, the more the $\mathrm{SiO}_{2}$ phase and the PI main chain, the stronger the interaction, which increases the energy required to break the macromolecular chain during the heating process and further improves the thermal stability of the composite film. 


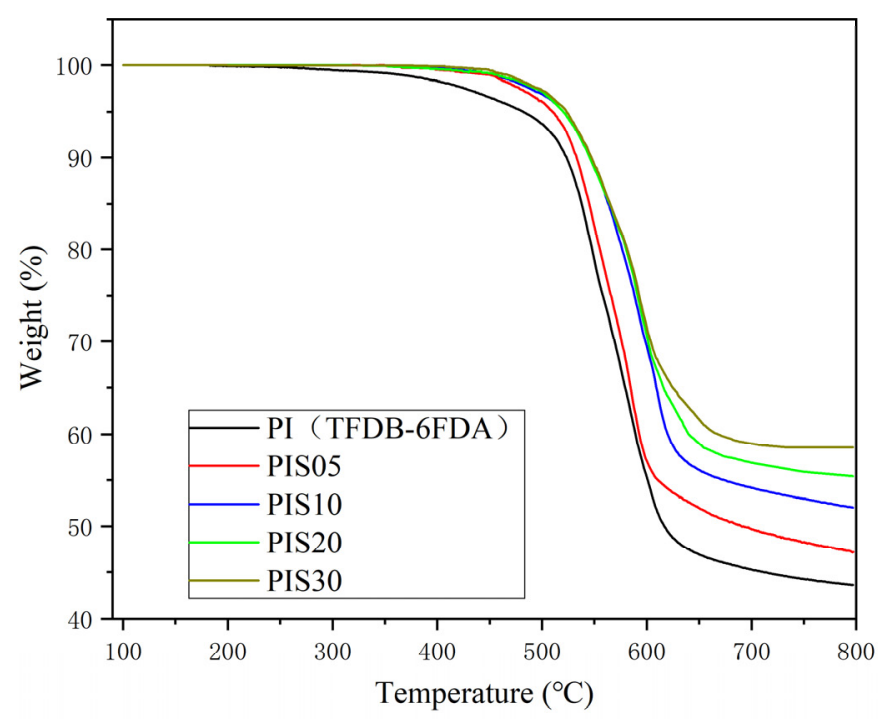

Figure 4. The TGA curves of the TFDB-6FDA system PI film, PIS05 and PIS10.

As the basic environment for spacecraft to operate in orbit, the space environment has a significant impact on the operation of the spacecraft and various systems. Studies have shown that there are space factors, such as ultraviolet radiation, solar wind protons, vacuum discharge, plasma, micrometeoroids, high and low-temperature cycles, ionizing radiation, and atomic oxygen [21]. The existence of these space factors would have a serious effect on the surface materials, electronic components, surface potential, and operating altitude of the spacecraft. As the covering layer material of spacecraft solar cells, the antiultraviolet radiation is the key point to be investigated among the above-mentioned space influence factors.

Solar ultraviolet radiation is the main form of solar electromagnetic radiation [22], and its wavelength range is between 200 and $400 \mathrm{~nm}$. The energy of ultraviolet photons is higher than $376.6 \mathrm{~kJ} / \mathrm{mol}$, and the bond energy of organic polymer molecules is generally $250-460 \mathrm{~kJ} / \mathrm{mol}$, so the energy of ultraviolet light is sufficient to break the organic chemical bonds, leading to the surface cracking or crosslinking reaction of polymer materials [23] and reducing the mechanical properties of materials. Therefore, this work uses the Cnlight HJ-1402 UV lamp to carry out the simulated space irradiation experiment, continuously irradiating pure PI film and PIS10 composite film for $264 \mathrm{~h}$, the ambient temperature is $21^{\circ} \mathrm{C}$, the humidity is $(30 \pm 5) \%$, and the irradiation power is $60 \mathrm{~W}$, The irradiation distance is $20 \mathrm{~cm}$. After the simulated irradiation experiment, the UH4150 ultraviolet-visible-nearinfrared photometer and the AGS-X $50 \mathrm{~N}$ material universal testing machine were used to investigate the light transmittance and mechanical properties of pure PI and PIS10 samples before and after irradiation.

After simulated ultraviolet irradiation, the maximum transmittance of pure PI decreased from $91.4 \%$ before irradiation to $89.8 \%$; the attenuation was about $1.75 \%$. The maximum transmittance of PIS10 decreased from $90 \%$ before irradiation to $88.5 \%$; the attenuation was about $1.67 \%$. The transmittance of pure PI and PIS10 both have a small attenuation, but the difference of attenuation is not significant, and the attenuation of PIS10 is slightly lower. This may be because when the doping amount of $\mathrm{SiO}_{2}$ is $10 \%, \mathrm{SiO}_{2}$ still exists in the PI matrix in the form of single particles and does not form a large inorganic phase. Therefore, after UV irradiation, the transmittance and attenuation have little change.

As shown in Table 2, the mechanical properties of pure PI and PIS10 changed greatly after UV irradiation. The attenuation of the tensile strength of PIS10 decreased from 19.76\% to $10.65 \%$ of pure PI film, the attenuation of elastic modulus decreased from $9.13 \%$ to $6.44 \%$ of pure PI film, and the attenuation of elongation at break decreased from $13.19 \%$ to $8.59 \%$ of pure PI film. The introduction of nano- $\mathrm{SiO}_{2}$ can effectively resist the effect of ultraviolet irradiation on the composite material. PI is irradiated to produce free radicals. 
In the process of binding free radicals to protons, chain breakage or crosslinking may occur. When the free radical combines with the proton, the molecular chain breaks from a long-chain to a relatively short fragment, and the decomposition reaction occurs. When two free radicals bind to each other, the two chains become a longer strand fragment, and a crosslinking reaction occurs. The fracture will decrease the tensile strength and elastic modulus, and the elongation at break. However, crosslinking will increase the tensile strength and elastic modulus and decrease the elongation at break. When the elongation at break, tensile strength, and modulus of elasticity decrease at the same time, it indicates that intramolecular fracture occurs, decomposition plays a major role; On the contrary, when the elongation at break decreases, while the tensile strength and modulus of elasticity increase, crosslinking plays a major role. The introduction of nano- $\mathrm{SiO}_{2}$ particles into the organic polymer matrix is to improve the bonding energy with the organic polymer [24] by taking advantage of the characteristics of small particle size, large specific surface area, strong hydroxyl reactivity on the surface and excellent anti-irradiation performance of $\mathrm{SiO}_{2}$, so as to improve the mechanical properties of the composites.

Table 2. The mechanical properties of the pure PI film and the PIS10 before and after irradiation.

\begin{tabular}{|c|c|c|c|c|c|c|c|c|c|}
\hline \multirow[b]{2}{*}{ Samples } & \multicolumn{3}{|c|}{ Tensile Strength (MPa) } & \multicolumn{3}{|c|}{ Elastic Modulus (GPa) } & \multicolumn{3}{|c|}{ Elongation at Break (\%) } \\
\hline & Before & After & $\begin{array}{c}\text { Attenuation } \\
(\%)\end{array}$ & Before & After & $\begin{array}{c}\text { Attenuation } \\
(\%)\end{array}$ & Before & After & $\begin{array}{c}\text { Attenuation } \\
(\%)\end{array}$ \\
\hline PI & 168 & 134.8 & 19.76 & 2.08 & 1.89 & 9.13 & 18.2 & 15.8 & 13.19 \\
\hline PIS10 & 198 & 176.9 & 10.65 & 2.64 & 2.47 & 6.44 & 12.8 & 11.7 & 8.59 \\
\hline
\end{tabular}

\section{Conclusions}

Using fluorine-containing diamine TFDB and fluorine-containing dianhydride 6FDA as monomers, a series of $\mathrm{PI} / \mathrm{SiO}_{2}$ with different $\mathrm{SiO}_{2}$ content were synthesized by the in situ polymerization method. The influence of coupling agent and $\mathrm{SiO}_{2}$ nanoparticle doping amount on the film structure and performance was studied. It was confirmed that the thermal imidization of the composite film was relatively complete, and the organic/inorganic phase formed a crosslinked network structure. Compared with traditional aromatic polyimide, fluorine-containing polyimide has excellent light transmittance (transmittance can reach $91.4 \%$ ). The cutoff wavelength of fluorine-containing PI can be extended from about $400 \mathrm{~nm}$ to about $350 \mathrm{~nm}$. Doping $\mathrm{SiO}_{2}$ nanoparticles into fluorine-containing PI reduces the light transmittance of the composite material as the content of $\mathrm{SiO}_{2}$ increases. Doping $\mathrm{SiO}_{2}$ nanoparticles into PI film has varying degrees of influence on the mechanical properties, is beneficial to the improvement of the radiation resistance and the thermal performance of $\mathrm{PI} / \mathrm{SiO}_{2}$ films. In addition, the introduction of a silane coupling agent can effectively inhibit the agglomeration of $\mathrm{SiO}_{2}$ nanoparticles, thereby forming a tighter crosslinked structure between organic and inorganic phases. In summary, the fluorinecontaining $\mathrm{PI} / \mathrm{SiO}_{2}$ nanocomposite is a suitable alternative material for flexible substrates in the aerospace field.

Supplementary Materials: The following are available online at https:/ / www.mdpi.com/2079-499 1/11/3/562/s1, Figure S1: The molecular formula of TFDB, 6FDA and obtained fluorine-containing PI, Figure S2: The XRD spectrum of the $\mathrm{SiO}_{2}$ nanoparticles, Table S1: The required amount of $\mathrm{PI} / \mathrm{SiO}_{2}$ films with various $\mathrm{SiO}_{2}$ contents, Table $\mathrm{S} 2$ : The most commonly used wave numbers of the imide group.

Author Contributions: Conceptualization, J.H. and J.L.; methodology, J.H.; software, J.H.; validation, J.H., G.Z. and B.D.; investigation, J.H.; resources, J.L.; data curation, J.H.; writting-original draft preparation, J.H.; writting-review and editing, J.L.; supervision, J.L.; project administration, J.H. All authors have read and agreed to the published version of the manuscript.

Funding: This work was partly supported by Major Science and Technology Projects of MilitaryCivilian Integration of Tianjin (Grant No.19ZXJRGX00040). 
Conflicts of Interest: The authors declare no conflict of interest.

\section{References}

1. Ding, M.X. Polyimide: The Relationship between Chemistry, Structure and Properties and Materials; Science Press: Beijing, China, 2006.

2. Yang, S.Y. Research on high temperature resistant polyimide resin. Polym. Bull. 2014, 12, $23-28$.

3. Yu, Y.Y.; Chien, W.C.; Tsai, T.W. High Transparent Soluble Polyimide/Silica Hybrid Optical Thin Films. Polym. Test. 2010, 29, 33-40. [CrossRef]

4. Tao, L.M.; Yang, H.X.; Liu, J.G.; Fan, L.; Yang, S.Y. Synthesis and characterization of highly optical transparent and low dielectric constant fluorinated polyimides. Polymer 2009, 50, 6009-6018. [CrossRef]

5. Ju, C.H.; Kim, J.C.; Chang, J.H. Synthesis and characterization of colorless polyimide nanocomposite films. Appl. Polym. Sci. 2007, 106, 4192-4201. [CrossRef]

6. Wang, X.; Zhao, X.H.; Wang, M.Z. The effects of atomic oxygen on polyimide resin matrix composite containing nano-silicon dioxide. Nucl. Instrum. Methods Phys. Res. Sect. B Beam Interact. Mater. At. 2006, 243, 320-324. [CrossRef]

7. Li, Z. The Molecular Design, Synthesis and Performance of Polyimide with Stability in Space Environment; Chinese Academy of Sciences: Beijing, China, 2011.

8. Hu, X.Y.; Wang, Y.W.; Cui, T.; Shang, Y.M.; Zhou, Y.; He, X.M. Preparation of PI microporous membrane for Lithium Ion batteries. Adv. Mater. Res. 2014, 104-107, 834-836.

9. Huang, C.; Li, J.; Xie, G. Low-dielectric constant and low temperature curable polyimide/POSS nanocomposites. Macromol. Mater. Eng. 2019, 304, 1900505-1900514. [CrossRef]

10. Cheng, J.D. Preparation and Properties of Polyimide/Nano-Silica Hybrid Film; Donghua University: Shanghai, China, 2007.

11. Li, Y.; Fu, S.Y.; Li, Y.Q. Improvements in transmittance, mechanical properties and thermal stability of silica-polyimide composite films by a novel sol-gel route. Compos. Sci. Technol. 2007, 67, 2408-2416. [CrossRef]

12. Mazov, I.N.; Ilinykh, I.A.; Kuznetsov, V.L.; Stepashkin, A.A.; Ergin, K.S.; Muratov, D.S.; Tcherdyntsev, V.V.; Kuznetsov, D.V.; Issi, J.P. Thermal conductivity of polypropylene-based composites with multiwal carbon nanotubes with different diameter and morphology. J. Alloy Compd. 2014, 586, S440-S442. [CrossRef]

13. Shahram, M.A.; Samaneh, S.D. Atructure-property relationships of low dielectric constant, nanoporous, thermally stable polyimides via grafting of poly(propyleneglycol) oligomers. Polym. Adv. Technol. 2008, 19, 889-894.

14. Boroglu, M.S.; Boz, I.; Gurkaynak, M.A. Structural Characterization of Silica Modified Polyimide Membranes. Polym. Adv. Technol. 2006, 17, 6-11. [CrossRef]

15. Liu, J.G.; Li, Z.; Yang, H.X. Synthesis and properties of high refractive index and high transparency semi-alicyclic polyimide Acta Polym. Sin. 2008, 5, 460-465. [CrossRef]

16. Liang, M.; Yang, A.; Zhu, Y.; Sun, S. Effects of nanoparticles' size and shape on the thermodynamic properties of PI/SiO 2 nanocomposites. Nano 2020, 15, 2050041. [CrossRef]

17. Ren, X.L.; Zhang, J.J.; Li, L.Y. Research progress of colorless and transparent polyimide film. China Plast. 2015, $29,5-13$.

18. Liu, J.G.; Zhang, X.M.; Kong, X.F. Colorless transparent high temperature resistant polyimide film preparation and performance research. Funct. Mater. 2006, 37, 1496-1499.

19. Liu, L.; Cao, C.; Ma, X.; Zhang, X.; Lv, T. Thermal conductivity of polyimide/AlN and polyimide/ (AlN plus BN) composite films prepared by in-situ polymerization. Macromol. Sci. A 2020, 57, 398-407. [CrossRef]

20. Cui, X.P.; Zhu, G.M. Research progress of polyimide nano-composite materials. Mater. Rep. 2015, 9, 12-17.

21. Fan, S.H.; Liu, Y.W.; Wen, Q. The effect of ultraviolet radiation on the properties of $\mathrm{EVOH} / \mathrm{nano}-\mathrm{SiO}_{2}$ composites. Chin. J. Packag. 2010, 2, 6-10.

22. Herndon, J.M.; Hoisington, R.D.; Whiteside, M. Deadly Ultraviolet UV-C and UV-B Penetration to Earth's Surface: Human and Environmental Health Implications. J. Geogr. Environ. Earth Sci. Int. 2018, 14, 1-11. [CrossRef]

23. Gao, J.F.; Hao, X.L.; Lu, W. Preparation and performance of a new pseudomorphic glass. Chin. J. Power Sources 2017, 41, 1136-1138.

24. Sasaki, A.; Aoshima, H.; Nagano, S.; Seki, T. A versatile photochemical procedure to introduce a photoreactive molecular layer onto a polyimide film for liquid crystal alignment. Polym. J. 2012, 44, 639-645. [CrossRef] 